\title{
A FILOSOFIA COMO POSSIBILIDADE DA EXPERIÊNCIA FILOSÓFICA NO ENSINO MÉDIO A PARTIR DO CONTEÚDO CURRICULAR
}

\author{
Caroline Moraes Brito ${ }^{1}$ \\ Joelson Alves Onofre ${ }^{2}$
}

RESUMO: Este artigo apresenta uma significativa contribuição no sentido de ampliar a reflexão e as discussões em torno do ensino de Filosofia, da sua identidade de conteúdo curricular e da prática educativa no Ensino Médio. Tem como objetivo geral discutir o ensino de Filosofia como uma disciplina filosófica do pensamento, considerando-a um componente fundamental no currículo da escola, desde quando propicia reflexão/formação no processo de aprendizagem. Enfoca a prática docente como elemento importante no processo de construção da identidade da disciplina Filosofia no currículo do Ensino Médio, pois o professor que se engaja nesse processo revela-se como um verdadeiro agente de mudanças, que através da sua responsabilidade profissional faz com que a permanência da filosofia no currículo do Ensino Médio seja profícua.

PALAVRAS-CHAVE: Currículo; Ensino Médio; Prática Docente; Reflexão Filosófica. 


\begin{abstract}
This article presents a significant contribution to enhance the reflection and discussions about the Philosophy of Education, its curriculum content identity and educational practice in High School. Its general objective is to discuss the teaching of Philosophy as a philosophical subject of thought, considering it as a key component in the school curriculum, from a relevant reflection / background in the process of learning.It focuses teaching practice as an important element in the process of the identity building of the subject of Philosophy in High School curriculum because the teacher who gets involved in this process, he/she is revealed as a true agent of change that through his/her professional responsibility makes the permanence of Philosophy profitable in High School curriculum .
\end{abstract}

KEYWORDS: Curriculum; High School; Teaching Practice; Philosophical Reflection. 


\section{INTRODUÇÃO}

Nos últimos anos, o enfoque nas condições e possibilidades do ensino de Filosofia adquiriu um grande desenvolvimento, principalmente, quando foi sancionada a Lei $\mathrm{n}^{\circ} 11.684$ de 2008, que alterou o art. 36 da Lei no 9.394, de 20 de dezembro de 1996, que estabelece as Diretrizes e Bases da Educação Nacional, para incluir a Filosofia e a Sociologia como disciplinas obrigatórias nos currículos do Ensino Médio.

Contudo, instaura-se nos meios acadêmicos a discussão e reflexão de como se dá a atuação dos professores de Filosofia com relação à elaboração e estruturação do currículo, como também da importância dos instrumentos pedagógicos no ensino de Filosofia, para assim legitimar a sua presença no cotidiano escolar da educação básica.

A Filosofia é bastante questionada enquanto disciplina. É necessário que os professores se conscientizem de que o seu ensino não deve ser considerado como um conteúdo a mais a ser ensinado, uma disciplina a mais a ser ensinada. O ideal é que o professor que tem a responsabilidade de aplicar tal disciplina, tenha em mente o quanto é necessário fazer com os estudantes não fiquem dependentes de livros didáticos, não desmerecendo, mas no sentido de não tender para os tão famosos "decorebas" de ideias e autores, prática tradicional muito presente nas escolas. Não existe receita pronta para aplicar a Filosofia, mas é recomendável que se preocupem com a melhor forma de aplicá-la. Recomenda-se a priorização de práticas que favoreçam a formação de jovens capazes de desenvolver seu próprio pensamento e crítica, formando cidadãos capacitados para enfrentar as diversas situações que 
poderão surgir em suas vidas. Essa disciplina é fundamental na vida de todo ser humano, visto que proporciona a prática de análise, reflexão e crítica em benefício do encontro do conhecimento do mundo e do homem.

Ministrada quase sempre por professores de outras áreas, a disciplina vive muitas vezes certo descaso e falta de identidade. $\mathrm{Na}$ rede pública, muitos professores assumem as aulas para completar carga horária, dada à condição de que não há número suficiente de professores com formação, apesar da oferta. Neste panorama geral, se faz necessária a discussão sobre o currículo da disciplina no Ensino Médio para que haja uma reflexão sobre a Filosofia como uma disciplina curricular, assim como as outras, e, portanto, possui identidade curricular.

O ensino de Filosofia precisa garantir o seu espaço, que vem sendo duramente reconquistado. É preciso tratar que concepção e que conteúdos de Filosofia devem ser desenvolvidos, sem perder de vista que ela deve ser pensada a partir de uma situação pedagógica de fato.

Este artigo consiste em refletir acerca do papel da Filosofia no Ensino Médio, que é nada mais do que realizar o aprendizado do pensamento. É mostrar que a principal meta da Filosofia nessa realidade educacional deverá estar na perspectiva de capacitar o estudante à prática filosófica, ao pensar autônomo, através de um saber articulado, organizado e planejado, mas para tanto, é preciso organizar o seu currículo com identidade própria, para que dessa forma conquiste o respeito e a credibilidade na comunidade escolar.

O presente texto foi produzido a partir de um Trabalho de Conclusão de Curso de Licenciatura em Filosofia pelo Plano 
Nacional de Formação de Professores da Educação Básica - PARFOR, na UESB (Universidade Estadual do Sudoeste da Bahia), Campus de Jequié/Bahia, com o tema Filosofia no Ensino Médio: Uma discussão sobre sua identidade curricular.

\section{ANÁLISE DOS CONTEÚDOS CURRICULARES PARA O ENSINO DE FILOSOFIA}

Se, por um lado, apresenta-se promissor o futuro da Filosofia no currículo do Ensino Médio; por outro, surge conjuntamente a necessidade da responsabilidade do profissional, para que este permaneça e seja profícuo, principalmente na tentativa de consolidação, através da organização curricular dessa disciplina no contexto escolar. Apesar dos avanços, a Filosofia ainda não ocupa um lugar definido no currículo do Ensino Médio, e, para tanto, a própria comunidade escolar contribui para a sua desvalorização, desencadeando problemas como: ensino que não corresponde às expectativas dos estudantes e abordagem fragmentada dos conteúdos. O que leva a constatar a necessidade de a Filosofia conquistar e definir seu espaço no fazer pedagógico da escola.

Para Ghedin (2009, p. 102),

Ao longo da história, a capacidade de decisão sobre os currículos ficou fora do alcance não só dos professores, mas também do próprio sistema educativo, à mercê das demandas externas, e foram os interesses e os valores 
daquelas pessoas que mais meios tem para decidir - as classes e os grupos hegemônicos - que historicamente determinaram a seleção e a organização dos conteúdos escolares. Essa situação de verdadeira amputação da capacidade de argumentação e fundamentação com respeito à função social da escola impediu que os professores fossem conscientes da importância que a seleção e a organização dos conteúdos tem em sua aplicação.

Além disso, no Ensino Médio, é muito comum a prática orientada pelo estudo dos autores (filósofos), e não pelos problemas da filosofia. Essa prática, geralmente é perpetrada por professores sem preparo e que acabam por desestimular os estudantes a tentarem resolver problemas autonomamente, bitolando-os apenas à interpretação do que disseram os filósofos. O estudante de filosofia é continuamente desestimulado a investigar os problemas filosóficos pelas aulas apenas expositivas, sem propiciar o debate, as quais não tem nenhum planejamento adequado pata tal. Lídia Maria Rodrigo (2009, p. 11) enfatiza:

Do ponto de vista didático, o grande desafio reside em saber como ensinar ou tornar acessível um saber especializado para esse público mais vasto e menos qualificado. Responder a esse desafio não é tarefa simples, uma vez que implica rever certos aspectos de uma tradição filosófica que frequentemente enfatizou a distância existente entre a filosofia e o senso comum.

É importante observar que, ao ensinar filosofia, a priorização de práticas que favoreçam a formação de jovens capazes de desenvolver seu próprio pensamento e crítica contribui para a 
formação de cidadãos capacitados para enfrentar as diversas situações que poderão surgir em suas vidas. O Ensino Médio é geralmente considerado pelos educadores como uma fase de consolidação do estudante jovem, de sua personalidade e seus desejos. A filosofia apresenta um papel importante e fundamental no sentido de colaboração para essa etapa.

A docência em filosofia convoca os professores como pensadores, mais do que como transmissores acríticos de um saber que supostamente dominam, ou como técnicos que aplicam estratégias didáticas em qualquer circunstância. Ensinar filosofia seria a atividade em que alguém transmite ao outro determinado conteúdo, neste caso, "de filosofia" ou "filosófico" não perdendo o foco de que aprender filosofia é conhecer a sua história, adquirir uma série de habilidades argumentativas ou cognitivas, desenvolver uma atitude diante da realidade ou construir um olhar sobre o mundo. Teles afirma (2010, p. 13):

Já que somos possuidores de raciocínio, a Filosofia não consiste apenas em indagações, mas em pensar com lógica. É, pois, um ato de reflexão metodicamente controlado. Ela busca respostas, mas não é uma conclusão a respeito de nada, e sim, mais apropriadamente, uma colocação de ideias, um verdadeiro debate.

O ensino de filosofia precisa estar em comum acordo com a prática do filosofar. É preciso que esse ensino seja filosófico, pois o que une os aprendizes à filosofia é o ato do filosofar. Sendo assim, produzirá atitude de problematizar as afirmações que são tidas como naturais e óbvias. Através do filosofar, os professores levam o estudante a pensar. Ensinar filosofia é refletir saberes. A 
função da filosofia nas escolas é mostrar aos jovens que é preciso questionar o mundo, para que assim possam transformá-lo.

Aspis e Gallo (2009, p. 30), assim expressam:

Passemos agora ao sentido político da disciplina. Ela constitui-se numa forma de organizar, de um impor uma ordem. Podemos falar, assim, de uma disciplina no pensamento, isto é, na imposição de uma ordem ao pensamento. E também cabe esta caracterização à filosofia.

O Planejamento para o ensino de filosofia deve considerar atitudes e práticas que levem o estudante a filosofar, a buscar pelo meio do pensamento construir um problema filosófico e, por conseguinte, tentar resolvê-lo.

Como já dissemos anteriormente, a experiência filosófica que pretendemos oferecer aos estudantes tem como objetivo criar uma disciplina, filosófica, no pensamento desses jovens e isso é útil para que eles possam pensar a si mesmos, de forma autônoma. Pensamos em um determinado ensino que dê instrumentos filosóficos para que o pensamento possa se fundamentar em sua liberdade. O que nos leva novamente à nossa ideia de criação de sub-versões. (ASPIS e GALLO, 2009, p. 23).

Saliente-se que o professor de filosofia trabalha os argumentos filosóficos a partir da tradição e da criatividade dos educandos. A faculdade crítica é, portanto, requerida como capacidade de análise e de compreensão de argumentos 
clássicos em filosofia e como aptidão para empreender criativamente a fundamentação de posicionamentos sobre os problemas e as soluções tradicionalmente disponíveis. Como a única adesão filosoficamente aceitável é a racional, a concepção de argumentação a ser assumida deve se afastar por completo das retóricas, das paixões ideológicas, das crenças religiosas, dos emotivismos e dos achismos, que teimam em rondar as classes de filosofia por má intenção, má formação ou ignorância de professores, sendo esses os perigos do filosofar nas aulas de filosofia.

Silvio Gallo (2012, p. 30) escreve sobre os efeitos que pode produzir o ensino de filosofia e afirma:

Dizendo de outro modo, um ensino de filosofia vale pelos efeitos que pode produzir. É certo que, no âmbito das grandes políticas, da educação maior, planejam-se efeitos para a filosofia: fazer de todos cidadãos, mesmo que por cidadãos entendam-se os consumidores no mercado global. Não deixa de ser uma filosofia prática, alheia ao enciclopedismo. Mas, por outro lado, uma filosofia criativa, voltada para os problemas vividos, visando equacioná-los conceitualmente, pode ser potencialmente revolucionária. Pode ser uma arma de produção da autonomia, mesmo no contexto de uma sociedade de controle.

$\mathrm{Na}$ verdade, o que se quer é que o estudante seja progressivamente capaz de defender suas próprias ideias, o que envolve uma compreensão rigorosa e profunda dos problemas que procura resolver, bem como uma capacidade para elaborar teorias, por assim dizer, originais e para 
defendê-las com sólidos argumentos. Para tanto, é necessário criatividade e criticidade. Criatividade para descobrir novas ideias, novos argumentos, ou novos problemas, isto é, argumentar inventando novos conceitos. E capacidade crítica para mostrar que sua teoria e seus argumentos são bons mediante a análise de conceitos tradicionalmente filosóficos. É tarefa do professor de filosofia facilitar o desenvolvimento de tais competências, bem como tê-las em mira no posterior processo avaliativo.

A presença da Filosofia no currículo escolar do ensino médio traz à tona discussões para os estudantes, que devem direcionar-se numa visão de mundo mais racional, abrangente e equilibrada, como também na orientação para o resgate da dimensão ética do conhecimento e na formação de valores. Em se tratando da questão dos conteúdos programáticos, percebe-se uma incerteza e desorientação entre os professores de filosofia no nível médio. Essa discussão é prioritária com relação ao ensino de filosofia, pois há uma percepção de que é necessário pensar uma identidade para a disciplina. Para superar obstáculos que aparecem na organização do currículo de filosofia, é preciso que o professor do ensino médio saiba pesquisar, pois desenvolverá técnicas que, mais tarde, lhe serão úteis no trabalho de docência. Com relação a essa questão, Ghedin (2009, p. 170) escreve:

Nesse caso, não se trata tanto da produção de novos conhecimentos, como se dá na pós-graduação stricto sensu, mas de uma mediação para a aquisição de saberes que possibilitarão a cada indivíduo enfrentar a complexidade do cotidiano em que experimenta sua existência. Afirma-se e assume-se que o processo 
de ensino de Filosofia e de outras disciplinas deve desenvolver-se orientado pelos padrões da pesquisa, como horizonte de produção do conhecimento, e não apenas pela transposição didática. Isso significa que o conhecimento existe como resultado de uma lógica de produção, mais do que de uma lógica de reprodução.

Em virtude da falta de contato com a filosofia no ensino fundamental, os estudantes manifestam desinteresse pela disciplina. Em boa parte, o desinteresse pelas aulas de filosofia deriva da falta de compreensão dos conteúdos ou do fato de que, muitas vezes, o estudante não consegue encontrar significação nesses conhecimentos. O professor tem certa cota de responsabilidade nisso. O interesse pela reflexão filosófica, assim como por qualquer outro assunto, só deverá ser despertado se os conteúdos se revelarem significativos para os estudantes, por isso o cuidado de se planejar, não perdendo de vista a realidade do nível médio. O que não falta é opção de escolha, basta que o professor tenha espírito de pesquisador e busque o conteúdo programático que seja significativo para esse nível. Pois,

Acontece que alguns adolescentes optam por negar a realidade, ficando na sensação de onipotência que lhes proporciona o fato de ter um mundo particular e isolado. Estes adolescentes evitam pensar, esquivam qualquer pergunta que se apresente, preferindo adormecer no sonho televisivo ou na hipnose de um videogame infindável que devore o tempo e cubra suas perguntas. Eles costumam dizer "para que você pensa tanto assim?", "de que adianta? ", ou seja, não admitem 
a possibilidade de sublimar suas pulsões mediante o diálogo e o pensamento criativo (BUSTAMANTE, 2009, p. 19).

A prática do ensino de filosofia é campo fértil para o método filosófico da compreensão de textos, principalmente dos grandes filósofos. A leitura desses textos é imprescindível. Certamente essa prática exige uma organização de análise do texto, de tal forma que conduza ao debate. Como bem colocado por Gallo e Kohan (2000, p. 123):

A leitura e análise de texto é outro procedimento indispensável à iniciação filosófica. Bem sabemos que aí se encontra uma das dificuldades do professor, diante da desvantajosa competição com os meios de comunicação de massa, já que o trabalho para se apropriar de um texto não exerce o mesmo fascínio da imagem e está muito distante da habitual "consciência flutuante" do espectador de tevê. Um bom recurso é começar com textos mais acessíveis, de acordo com o nível de alunos, usando desde artigos de jornal, poesia, crônicas, intercalados com trechos de ensaios filosóficos, até que estes possam predominar sobre os primeiros.

Outro método é aquele que organiza a disciplina numa visão sistemática, destinada à sua transmissão. Trata-se de expor o conteúdo filosófico para uma maior compreensão, consistindo assim, na retenção de informações terminológicas. Quanto a isso, Cortella (2009, p. 60) assevera: 
Por isso, estamos sugerindo que o professor balize seu trabalho no desenvolvimento de curso por um princípio orientador: fazer de cada unidade que se complete, sem uma preocupação desmesurada em "cumprir" um programa. A realização ou atingimento do objetivo principal já apontado pode ser obtida pelo processamento pleno de qualquer uma das unidades, demore-se o tempo que for preciso.

O modelo mais tradicional de currículo para o ensino de Filosofia é a abordagem histórica centrada na História da Filosofia e consiste em apresentar uma sequência cronológica dos pensadores, numa abordagem que prescinde do contato direto com o pensamento dos filósofos, restringindo-se a uma exposição e síntese da vida, obra e principais ideias dos filósofos.

Os períodos históricos podem ser subdivididos em: A História da Filosofia Antiga, subdividida em três períodos: pré-socrático, clássico e helenístico; a História da Filosofia Medieval, que pode, por exemplo, ser dividida em dois períodos: Patrística e Escolástica; a Filosofia Moderna, que, por sua vez, é geralmente demarcada por áreas: Teoria do Conhecimento, Filosofia Política, Metafísica e, por vezes, por fenômenos como o Iluminismo. Quanto à História da Filosofia contemporânea, em geral, não se a divide em períodos, mas correntes ou escolas filosóficas, como a fenomenologia e o existencialismo; o liberalismo econômico, o marxismo e outras, assim como acontece no período helenístico o qual normalmente é estudado a partir das "escolas". 
É um tipo de conteúdo que veda a possibilidade de se compreender os filósofos na sua singularidade. Muitas vezes as aulas de história da filosofia não apresentam aos alunos os textos originais dos filósofos, limitando-se às exposições do professor, distanciando ainda mais o aluno da filosofia. Por outro lado, se no curso, ensinar a ler os textos filosóficos, estará aproximando o aluno do filosofar, pois ensinará a recriar o pensamento de algum filósofo, é importante salientar que deve-se ler filosofia como se lê poesia, revivendo-a, encarnando-a, emocionando-se com ela, reinventando-a. Assim retratam Aspis e Gallo (2009, p. 55 , grifo dos autores):

Dessa maneira, a problemática da história da filosofia no ensino da filosofia começa a se apresentar de outra forma. Lembrando Kant, o ensino de filosofia precisa ser ativo, precisa ser processo, precisa estar para além da mera reprodução e assimilação do que pensaram os filósofos ao longo da história; por outro lado, lembrando Hegel, não é possível exercitar o ato de filosofar sem o recurso àquilo que foi historicamente produzido. Deleuze nos ajuda, por sua vez, a encontrar na história da filosofia, como arte do retrato, uma perspectiva de retomar criativamente aquilo que foi pensado e repensado pela humanidade, a partir disso criando novos conceitos para ressignificar os problemas filosóficos que vivemos hoje.

Já os temas filosóficos apresentam um aspecto indisciplinar, ou seja, comunicam-se facilmente com outras áreas do conhecimento. Hoje, o ensino médio já solicita 
dos professores que trabalhem de forma interdisciplinar, que haja o diálogo entre as áreas de conhecimento. No caso da filosofia, ela precisa dialogar com outras disciplinas das Ciências Humanas, e o estudo dos temas filosóficos facilita esse tipo de comunicação.

[...] pensamos que uma abordagem de natureza temática é mais adequada ao ensino da filosofia, se pretendemos um ensino ativo, que oportunize experiências de pensamento. Através de temas filosóficos, pensamos ser mais viável sensibilizar os estudantes para o pensamento. Um exemplo. Talvez não desperte tanto interesse do estudante, em um primeiro contato, saber o que pensou um filósofo como Platão, que viveu há dois mil e quinhentos anos atrás. Mas o aluno poderá estar muito mais aberto para pensar sobre o amor, algo que faz parte de seu cotidiano, de sua vida. E, através da tematização do amor, poderemos, por exemplo, ler o diálogo $\mathbf{O}$ Banquete e Acompanhar a teorização sobre o tema produzida pelo mesmo Platão (ASPIS e GALLO, 2009, p. 51-52, grifo dos autores).

O planejamento que prioriza os temas da filosofia percorre o pensamento de vários filósofos, nos diferentes períodos históricos. Dessa forma, a análise tende a ser superficial, porém, permite ao estudante a comparação do pensamento dos filósofos em torno de determinados temas. Muitas vezes, comparam-se os pensamentos dos filósofos em cada período histórico. 
Quando a abordagem por temas tiver como foco dois ou mais filósofos em diferentes períodos históricos, a atividade tende a ser superficial, mas por outro lado permite a comparação do pensamento dos filósofos em torno de determinado tema. Por isso,

O ensino de Filosofia no espaço escolar não consiste em ensinar a ler e escrever no sentido restrito, mas em usar as estratégias de leitura e de escrita como formas para o desenvolvimento do pensamento crítico. Para isso, é necessário que tanto a leitura quanto a escrita do aluno possam situar-se na criticidade como elemento que possibilita a construção da cidadania. (GHEDIN, 2009, p. 160).

Há uma exigência muito forte para o ensino de filosofia, que trata da impossibilidade de dissociar a História da Filosofia dos Temas. Em qualquer eixo em torno do qual estejam organizados os conteúdos, haverá uma interação entre eles. Evidentemente, um ou outro será priorizado, mas não é possível excluir os outros. Quanto a isso,

Acreditamos ser um bom caminho o de pedir que os alunos leiam filosofia como leem poesia, isto é, ler a coisa revivendo-a, entrando nela, tornando-a experiência de quem leu, podendo daí reinventála segundo a emoção que desperta. Para alcançar o objetivo de ensinar os alunos a filosofarem, a poderem eles mesmos criar filosofia, o papel do professor seria o de conduzir os alunos para que possam entrar no texto filosófico, para poder desmontá-lo e remonta-lo 
ou montar uma outra filosofia com as mesmas peças ou com parte delas (ASPIS e GALLO, 2009, p. 96, grifo dos autores).

A organização dos conteúdos é uma orientação para o desenvolvimento das aulas. No entanto, o que determina a aproximação entre a reflexão filosófica e a experiência do estudante é a abordagem didática e o método que serão realizados pelo professor.

No entanto, Gallo e Kohan (2000, p. 195), de forma muito coerente, salientam:

Pensamos que uma educação para a autonomia, no sentido da formação de indivíduos que possam escolher por si mesmos em que mundo querem viver, só pode ser tal se nela tiver lugar a filosofia. Pois apenas assim o jovem poderá ter acesso à aventura do pensamento como experiência radicalmente crítica e criativa, descortinando-se para ele aquela multiplicidade de elementos que já trabalhamos aqui. E só assim nossos jovens poderão, de fato, assumir livremente a condição de cidadãos. Para não ficar no vazio da letra da lei, que enuncia, mas nada garante, se não tivermos uma ação efetiva no cotidiano de nossas lides educacionais.

A discussão aqui implementada só fundamenta que a inserção da Filosofia no nível médio, além de abrir um espaço para o desenvolvimento intelectual dos estudantes, estimula a discussão de conceitos, dando oportunidades de descobrir os ideais que nortearão as suas vidas e o fazer educacional, onde deixa de ser o de memorizar "o conteúdo" 
e passa a ser de orientá-los na busca de suas necessidades intelectuais, através do desenvolvimento do raciocínio, do questionamento e da investigação. O estudo da Filosofia é uma busca de formar uma geração mais atenta, crítica e apta a discutir, escolher e decidir por si mesma.

\section{CONSIDERAÇÕES FINAIS}

Tendo em vista a amplitude das questões colocadas neste artigo, faz-se necessário ressaltar a importância e a necessidade da Filosofia nas escolas, isto porque o papel da educação é levar o estudante à autonomia, à independência e à capacidade de formular as próprias opiniões e a Filosofia propicia essa realidade através dos seus conteúdos que são universais e instigantes, e ainda possibilita o desenvolvimento de habilidades necessárias a um pensar crítico e reflexivo.

É preciso propiciar aos estudantes ler e se expressar para que possam tentar modificar o seu entorno, a sua realidade, mas para tal é preciso argumentar, é preciso descobrir sobre "o que" argumentar.

O papel do professor passa a ser de muita importância porque compete a ele desmitificar o conservadorismo existente no ambiente escolar, principalmente com relação a essa disciplina, como também o "des" compromisso dos estudantes com a Filosofia. É importante que ela passe a ser vista com a devida importância no currículo, já que é obrigatória a sua presença no processo educacional.

Se por um lado, apresenta-se promissor o futuro vinculado à reintrodução da Filosofia no currículo do Ensino Médio; por outro, surge conjuntamente a necessidade da 
responsabilidade do profissional em questão para que este permaneça e seja profícuo. Para tanto, não é indispensável apenas o "assumir" o mercado de trabalho, mas também, estar apto a desenvolver o ensino da disciplina na realidade em que está inserida.

Ao detectar profissionais de outras áreas assumindo a "cadeira" de Filosofia, só se confirmará que esses não são aptos para ministrar as aulas da referida matéria. É transparente o prejuízo que isto causa para firmar-se o ensino de Filosofia no contexto escolar e para a formação do estudante. Entretanto, este não é o único empecilho para a permanência da Filosofia no currículo médio, ou seja, o da falta de formação. Há a questão do mau profissional que, por falta de compromisso ou mesmo descaso, não contribui para um amadurecimento destas questões e do ensino como um todo. O futuro da Filosofia na Educação Básica é incerto, porém, a sua permanência no currículo escolar dependerá mais do que nunca da prática responsável do docente, se assim for, apresenta-se com um futuro promissor.

A sustentação da Filosofia no Ensino Médio depende das experiências positivas dadas ao cotidiano escolar, pois para ela ser oferecida nesse nível de ensino, houve uma história de luta que não pode ser desconsiderada. É preciso que a sua presença no currículo escolar atenda às demandas sociais, principalmente à expectativa de ampliação de visão de mundo e mudanças sociais.

Nesta atual sociedade, voltada à tecnologia, parar para pensar é o mesmo que perder tempo. Assim, a tarefa da Filosofia na educação não é nada fácil. É a de convidar o estudante a uma superação das concepções superficiais da 
sociedade onde está inserido, ensinando-o a pensar de forma racional, abstrata e abrangente sobre a realidade. É estimular o estudante a refletir sobre si mesmo para aprender a se criticar e a também refletir sobre o mundo para compreendêlo e, depois disto, buscar saber qual o seu papel diante do mundo que o cerca e diante do seu próximo.

Enfim, dada a longevidade histórica e a importância cultural da Filosofia para a civilização ocidental, de uma coisa há certeza, como disciplina no Ensino Médio ela merece ainda muita atenção por parte dos intelectuais, docentes e pedagogos envolvidos com o processo educacional, sobretudo no Brasil.

\section{NOTAS}

${ }^{1}$ Licenciada em Letras Vernáculas pela Universidade Estadual do Sudoeste da Bahia - UESB. Licenciada em Filosofia pela UESB - Plano Nacional de Formação de Professores da Educação Básica - PARFOR. Especialista em Linguística aplicada ao texto pela UESB. Especialista em Literatura Brasileira pela Universidade Salgado Oliveira - UNIVERSO. Professora de Filosofia e Língua Portuguesa da Rede Estadual de Ensino do Estado da Bahia no Ensino Médio. Professora de Língua Portuguesa da Rede Municipal de Ensino de Jequié. E-mail: linebrito68@yahoo.com.br.

${ }^{2}$ Especialista em Educação e Relações Etnicorraciais - UESC. Mestre em Educação pela UFBA (Universidade Federal da Bahia). Professor Substituto de Filosofia na Universidade Estadual de Feira de Santana - UEFS. E-mail: jaonofrecp@yahoo.com.br. 


\section{REFERÊNCIAS}

ASPIS, Renata Lima; GALLO, Silvio. Ensinar Filosofia: um livro para professores. São Paulo: Alta Mídia e Educação, 2009.

BRASIL. Lei no 9394/96, de 20 de dezembro de 1996. Estabelece as diretrizes e bases da Educação Nacional. Disponível em: http://www.planalto.gov.br/ccivil_03/leis/19394.htm Acesso em: 30 mar. 2016.

BRASIL. Lei $n^{\circ} 11.684$, de 02 de junho de 2008. Altera o art. 36 da Lei no 9.394, de 20 de dezembro de 1996, que estabelece as diretrizes e bases da educação nacional, para incluir a Filosofia e a Sociologia como disciplinas obrigatórias nos currículos do ensino médio. Disponível em: http://www.planalto.gov.br/ccivil_03/_ Ato2007-2010/2008/Lei/L11684.htm Acesso em: 30 mar. 2016.

BUSTAMANTE, Ani. Filosofando na escola. Petrópolis: Vozes, 2009.

CORTELLA, Mário Sérgio. Filosofia e ensino médio: certos porquês, alguns senões, uma proposta. Petrópolis: Vozes, 2009.

GALLO, Silvio. Metodologia do ensino de filosofia: uma didática para o ensino médio. Campinas: Papirus, 2012.

GALLO, Silvio; KOHAN, Walter Omar (Orgs.). Filosofia no ensino médio. Petrópolis: Vozes, 2000. 
A FILOSOFIA COMO POSSIBILIDADE DA EXPERIÊNCIA FILOSÓFICA...

GHEDIN, Evandro. Ensino de filosofia no ensino médio. São Paulo: Cortez, 2009.

RODRIGO, Lidia Maria. Filosofia em sala de aula: teoria e prática para o ensino médio. Campinas: Autores Associados, 2009.

TELES, Maria Luiza Silveira. Filosofia para o ensino médio. Petrópolis: Vozes, 2010. 